\title{
Detection of c-Ki-ras mutations in bile samples from patients with pancreatic and biliary
}

\section{cancers}

\author{
S O'Mahony, M Longfellow, M J McMahon, A T R Axon, P Quirke
}

\begin{abstract}
Aim-To determine whether c-Ki-ras mutations can be detected in bile from patients with biliary strictures caused by pancreatic cancer and other biliary tumours, with a view to developing bile c-Kiras mutations as a non-invasive diagnostic marker of pancreatic cancer.

Methods-Bile was collected from 89 subjects (47 controls (including patients with bile duct stones or benign stricture), 20 patients with pancreatic cancer, 11 with cholangiocarcinoma, five with ampullary cancer, and six with metastatic biliary obstruction) referred for endoscopic retrograde cholangiopancreatography. DNA was extracted from bile and c-Ki-ras codon 12 mutations were detected using PCR and a restriction enzyme digestion method.
\end{abstract}

Results-c-Ki-ras mutations were detected in $10(50 \%)$ of 20 patients with pancreatic cancer, in one $(9 \%)$ of 11 with cholangiocarcinoma, and in two (33\%) of six patients with metastatic biliary obstruction (primary tumours: colon and prostate). C-Ki-ras mutations were not detected in the controls and patients with ampullary cancer.

Conclusions-The sensitivity of this test is too low at $50 \%$ to recommend its use clinically, but with refinement has potential as a diagnostic marker for pancreatic cancer.

(f Clin Pathol: Mol Pathol 1995;48:M316-M318)

Centre for Digestive Diseases, The General Infirmary at Leeds, Great George Street, Leeds LS1 3EX

S O'Mahony

M J McMahon

A T R Axon

P Quirke

Molecular Oncology, Centre for Cancer

Research, Algernon Firth Building,

University of Leeds, Leeds LS2 9JT

$M$ Longfellow

P Quirke

Correspondence to: Dr Seamus O'Mahony, Dr Seamus O'Mahony, Clinical Sciences Building Clinical Sciences Building
(Level 7), St James's (Level 7), St James's University

AS97TF. 25 July 1995
Keywords: Bile, c-Ki-ras, pancreatic cancer, biliary cancer.

Most (over 90\%) of pancreatic adenocarcinomas harbour mutations in codon 12 of the c-Ki-ras gene. ${ }^{12}$ Recent studies have reported the presence of the oncogene in pancreatic juice $^{3}$ and pancreatic duct brushings ${ }^{4}$ in over $90 \%$ of patients with pancreatic cancer, suggesting that the oncogene might be useful as a diagnostic marker of pancreatic cancer. Pancreatic juice is, however, relatively difficult to obtain endoscopically, and performing brushings of the pancreatic duct adds significantly to procedure time of endoscopic retrograde cholangiopancreatography (ERCP). Bile is easy to collect endoscopically, particularly when a stent is inserted. Obstructive jaundice is a frequent presentation of pancreatic cancer, and these patients are generally man- aged by ERCP, which has the advantage of being a combined diagnostic and therapeutic modality. The aim of our study was to determine whether c-Ki-ras mutations can be detected in bile from patients with biliary strictures caused by pancreatic cancer and other biliary tumours, with a view to developing bile c-Ki-ras mutations as a non-invasive diagnostic marker of pancreatic cancer.

\section{Methods}

Bile was collected from a total of 89 subjects referred for ERCP. Demographic details are shown in the table. These 89 subjects included 47 controls ( 20 patients with pancreatic cancer, 11 with cholangiocarcinoma, five with ampullary cancer, and six with biliary obstruction caused by metastases). The control group consisted of 30 patients with bile duct calculi (11 patients with a normal biliary tree, one patient with a postoperative biliary leak, and three with benign biliary strictures caused by chronic pancreatitis, Mirizzi syndrome, and iatrogenic post-cholecystectomy bile duct injury). The patient with chronic pancreatitis had previously undergone a cystjejunostomy for pseudocyst following alcoholic pancreatitis. In the 20 patients with pancreatic cancer, a tissue diagnosis was achieved in four only: three by laparotomy and the other by ascitic fluid cytology. Percutaneous fine-needle aspiration biopsy was unsuccessful in four cases, the material obtained being insufficient for diagnosis, consisting of necrotic tissue and red blood cells. The diagnosis of pancreatic cancer in the remaining 16 was based on radiological (computed tomography/ERCP) appearances, and clinical follow up: all 20 patients have died, with a median survival of six months (range one to 16 months). Four patients underwent surgery: one had a Whipple's procedure, two had palliative biliary by-pass procedures, and the other a gastrojejunostomy. Of the 11 patients with cholangiocarcinoma, tissue diagnosis was achieved in one only, by laparoscopic biopsy of omental deposits. In the remaining 10 patients, diagnosis was based on typical radiological appearances (all had hilar strictures) and clinical follow up: nine of these 10 patients have died, with a median survival of five months (range one to 18 months). One patient is alive at 19 months following stenting, and none underwent surgery. In the five patients with ampullary cancer, tissue diagnosis was achieved in all by endoscopic biopsy. In the six patients with metastatic biliary obstruction, 


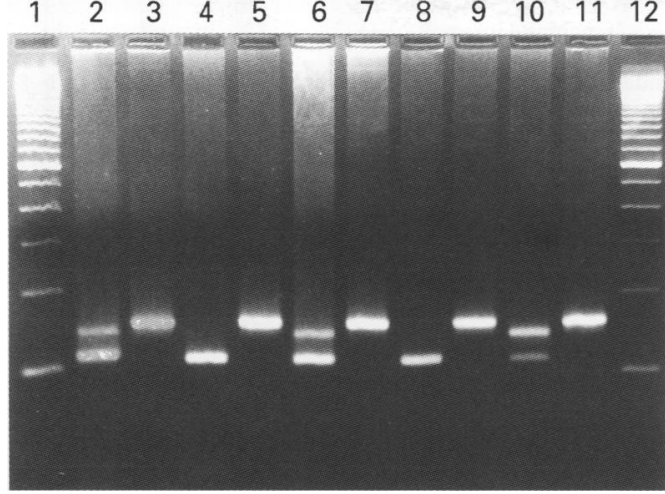

BstN1 digest: the samples are run in pairs of digested and undigested products (even-numbered lanes contain digested products). Lanes 2,6 and 10 contain samples with $\mathrm{c}-\mathrm{Ki}$ ras codon 12 mutations. Lanes 1 and 12, 100 base pair marker.

the primary tumours were colon $(n=3)$, oesophagus $(n=1)$, stomach $(n=1)$, and prostate $(n=1)$.

\section{$R A S$ MUTATION ANALYSIS}

DNA extraction

Bile was collected endoscopically at ERCP. In those cases where a biliary stent was inserted, bile was aspirated via the stent "pusher" tube. Otherwise, bile was collected via a standard cannula. The bile was centrifuged, and the supernatant discarded. The sediment was collected in an Eppendorf tube and incubated with $2 \mathrm{mg} / \mathrm{ml}$ proteinase $\mathrm{K}$ (Sigma, Poole, Dorset, UK) and $1 \%$ sodium dodecyl sulphate for 24 hours at $37^{\circ} \mathrm{C}$. The DNA was extracted using phenol chloroform extraction and ethanol precipitation. The DNA pellet was dissolved in $25 \mu \mathrm{l}$ water and amplified by PCR.

\section{Polymerase chain reaction}

Primer sequences described by Jiang et $a \hat{l}$ contained altered base pairs which create restriction enzyme digestion sites that permit the detection of mutations in the first two bases of c-Ki-ras codon 12. The primers were synthesised on an Applied Biosystems DNA synthesiser. The DNA was amplified using PCR to produce a 157 base pair fragment containing c-Ki-ras codon 12. The PCR conditions have been described previously. ${ }^{6}$ In each PCR a negative control was included in which the DNA was omitted. A volume of $12 \mu \mathrm{l}$ of the PCR product was then visualised on a $2 \%$ GTG agarose gel stained with ethidium bromide.

Bst $N 1$ restriction enzyme digestion

In a total volume of $25 \mu \mathrm{l}, 16 \mu \mathrm{l}$ of the PCR product was digested with $B s t \mathrm{~N} 1$ at $60^{\circ} \mathrm{C}$ over-

Demographic details of patients and $c-K i$-ras mutation positivity rates

\begin{tabular}{llcc}
\hline Subject group & Median (range) age (years) & $M / F$ ratio & Ras positivity \\
\hline Controls $(\mathrm{n}=47)$ & $72(28-96)$ & $23 / 24$ & $0(0 \%)$ \\
Pancreatic carcinoma $(\mathrm{n}=20)$ & $71(54-96)$ & $7 / 13$ & $10(50 \%)$ \\
Cholangiocarcinoma $(\mathrm{n}=11)$ & $69(49-81)$ & $7 / 4$ & $1(9 \%)$ \\
Ampullary carcinoma $(\mathrm{n}=5)$ & $82(73-92)$ & $4 / 1$ & $0(0 \%)$ \\
Metastases $(\mathrm{n}=6)$ & $58(27-77)$ & $6 / 0$ & $2(33 \%)$ \\
\hline
\end{tabular}

night under the conditions recommended by the enzyme suppliers (Boehringer Mannheim, UK). The digestion products were analysed on a 3\% Nu Sieve agarose gel (FMC Bioproducts) stained with ethidium bromide. Sample analysis on agarose gel is shown in the figure.

\section{Results}

c-Ki-ras codon 12 mutations were detected in $10(50 \%)$ of the 20 patients with pancreatic cancer, in one $(9 \%)$ of the 11 patients with cholangiocarcinoma, and in two $(33 \%)$ of the six patients with metastatic biliary obstruction (primary tumours: colon and prostate) (table). Mutations were not detected in any of the controls or the patients with ampullary cancer.

\section{Discussion}

c-Ki-ras mutations were detected in patients with malignant disease (or presumed malignant disease) only. In relation to pancreatic cancer the sensitivity ( $50 \%$ ) was disappointing, given the high prevalence $(>90 \%)$ of c-Ki-ras mutations in pancreatic cancer. There are two possible explanations for the low sensitivity: (1) low cellularity in some bile samples, and (2) relative insensitivity of the PCR technique. It is likely that brushings of biliary strictures would be more likely to contain tumour cells than bile-biliary brush cytology has a much higher sensitivity compared with bile exfoliative cytology in the diagnosis of malignant bile duct strictures. ${ }^{7}$ The PCR technique we have used detects mutations at codon 12 only. It is likely that more sophisticated molecular techniques (for example, amplification refractory mutation system, single strand conformation polymorphism, DNA ligase PCR) or more sensitive detection methods (for example, gene scanning on a DNA sequencer) might increase the mutation positivity rate, and thus the value of the test.

Ras mutations were detected in patients with metastatic biliary obstruction, and in one patient with cholangiocarcinoma. The presence of the oncogene therefore does not establish a definitive diagnosis, but in the appropriate clinical setting is strong evidence of pancreatic cancer. There was, however, a small number (three) of patients with benign biliary strictures. The tissue diagnosis rate in our patients with pancreatic cancer was low at $20 \%$, but a positive tissue diagnosis is achieved in only a minority of patients with pancreatic cancer in this country-for example, in the Yorkshire region, of patients registered with the Regional Cancer Registry in 1993 and 1994, a positive tissue diagnosis was achieved in only $35.6 \%$ and $36.4 \%$, respectively (Yorkshire Regional Cancer Registry: personal communication). In summary, we have detected bile c-Ki-ras mutations in 10 of 20 patients with pancreatic cancer. The sensitivity $(50 \%)$ is therefore too low to recommend the clinical application of this test, but this approach has potential as a means of establishing a diagnosis at the molecular level in patients with pancreatic cancer. 
This work was supported by the Ivy Hobson Bequest from the Special Trustees of the United Leeds Teaching Hospitals NHS Trust. We are grateful to the referring physicians and surgeons for allowing us to study patients under their care. We thank the Endoscopy Nurses of the Leeds General Infirmary for their Endoscopy Nurses of the Leeds

1 Almoguera C, Shibata D, Forrester K, Martin J, Arnheim N, Perucho M. Most human carcinomas of the exocrine pancreas contain mutant c-K-ras genes. Cell 1988;53:54954.

2 Hruban RH, van Mansfield ADM, Offerhaus GJA, van Weering DHJ, Allison DC, Goodman SN, et al. K-ras oncogene activation in adenocarcinoma of the human pancreas. A study of 82 carcinomas using a combination of mutant-enriched polymerase chain reaction analysis and mutant-enriched polymerase chain reaction analysis and 1993;143:545-54.
3 Trumper LH, Burger B, von Bonin F, Hintze A, von Blohn $\mathrm{G}$, Pfreundschuh $\mathrm{M}$, et al. Diagnosis of pancreatic adcreatic secretions. Br f Cancer 1994;70:278-84.

4 Van Laethem J-L, Vertongen P, Deviere J, Van Rampelbergh $\mathrm{J}$, Rickaert F, Cremer M, et al. Detection of c-Ki-ras gene codon 12 mutations from pancreatic duct brushings in the codon 12 mutations from pancreatic duct brushings in
diagnosis of pancreatic tumours. Gut 1995;36:781-7.

5 Jiang W, Kann SM, Gillem JG, Lu S-H, Weinstein B. Rapid detection of ras oncogenes in human tumours: applications to colon, esophageal and gastric cancer. Oncogene 1989;4: 923-8.

6 Bell SM, Kelly SA, Hoyle JA, Lewis FA, Taylor GR Thompson $\mathrm{H}$, et al. $\mathrm{C}-\mathrm{Ki}$-ras gene mutations in dysplasia and carcinoma complicating ulcerative colitis. $\mathrm{Br}$ f Cancer $1991 ; 64: 174-8$

7 Kurzawinski T, Deery A, Dooley JS, Dick R, Hobbs KEF, Davidson BR. A prospective controlled study comparing brush and bile exfoliative cytology for diagnosing bile duct strictures. Gut 1992;33:1675-7.

ב⿱一𫝀) 